\title{
Optimization of Container Storage under Reshuffling Constraints in a Seaport
}

\author{
Sara Souaini \\ LARILE Laboratory, OSIL Team Ensem, Hassan II \\ University of Casablanca, Casablanca, Morocco
}

\author{
Jamal Benhra \\ LARILE Laboratory, OSIL Team Ensem, Hassan II \\ University of Casablanca, Casablanca, Morocco
}

\begin{abstract}
This contribution presents a mathematical model that manages container storage at the beginning of a time horizon, in a container terminal, ignoring incoming containers.

For the solution of this static case of the container storage problem, a mathematical representation of the problem as an integer linear program will be studied.

The objective is to minimize the expected total distance between storage locations and their exits, considering the shuffling constraints.

A complexity analysis of the problem has been performed, and then graph theory notions has been employed by reducing the problem to incompatibility graphs that make the storage constraints more clearly visible.

An application on a computer solver will then be performed on small instances.
\end{abstract}

\section{Keywords}

Ports, Optimization, Mathematical Modeling, Container Storage, Storage Strategies, solver, reshuffling.

\section{INTRODUCTION}

With the evolution of the containerization and the considerable number of containers passing through seaports, the problem of container storage became one of the main issues. It has a considerable impact on the efficiency of other port operations.

A maritime container terminal is divided into two main areas, each characterized by its own handling operations and equipment. In the quayside area, ships are loaded and unloaded by gantry cranes. In the land area, the gantry cranes are used. Another equipment, which is used for the transport, ensures the connection between these two areas.

In order to improve the efficiency of port operations, it is essential to identify and solve a series of optimization problems such as: planning the movements of transport trucks, planning the operations of yard gantries, planning the operations of quay gantries and allocating containers to storage areas.

The objective of this project is to find an optimal storage plan that specifies the ideal storage location for each container and that considers the actual storage constraints.

The storage yard is a crucial resource in a container terminal. The degree of efficiency in its management is reflected in the overall productivity of the port.

As a result of the reduction in the cost of transporting goods and merchandise due to containerization, container flows have increased significantly in ports. In fact, in 2005 the flow of containers worldwide exceeded 21.6 million TEUs (Twentyfoot equivalent units) [10]. The direct consequence of this is a dizzying growth in the number of containers that stay in a port at the same time, making the storage space on the ground insufficient. One solution to this problem could be to increase the surface area of the storage yards, but this is ineffective because the number of containers that enter a port at the same time is constantly increasing as the means of transport develop. In addition, the cost of land is high. Another solution to this problem is to use the advantage of standardization of container sizes, which makes it possible to stack containers. To be effective, the stacking of containers must also consider departure dates of containers. Randomly arranging containers in a stack can make some containers inaccessible during retrieval. Thus, it will be necessary to perform container rearrangement operations just prior to the departure times of some containers. These operations are called reshuffles and are considered unproductive movements that consume time and slow down port operations. To avoid this kind of inconvenience, several research works have been carried out in the last decades to propose efficient storage methods and decision support systems. These are the subject of this study, in which both analytical and numerical methods are reported.

\section{LITERATURE REVIEW}

\subsection{Definitions and roles of ports}

Ports have multiple roles in the maritime industry and are part of a complex network. They are interfaces between the sea and land transport. However, there are many definitions of a port. Therefore, some of them will be cited, starting with the one given by Stopfords that characterizes a port as:

"A geographic area where ships are put alongside land in order to load and unload cargo - usually a deep-water area such as a bay or river mouth." [11]

This definition is straightforward, but it provides some insight into the fundamental role of a port. At the same time, it is important to understand that the role of a port is more complex than just being a waterfront location. Today, ports are key elements in the global transportation system, because without them the ships would be useless in the transportation of goods, since there would be no place where they could be loaded or unloaded. Therefore, ports can be seen as facilitators of multi-modal trade (between land and sea).

Hall's recent studies describe the role of ports in a global logistics chain as: "A physical manifestation of the logistical functions that these locations serve in global and global commodity trade. " [12]

This definition gives insight into the complexity of the chain of activities that are related to ports. This is reflected in the definition of a port presented in the annual report of the Port of Antwerp, which states that:

"The port is like a link in an interconnected logistics chain that extends from the overseas foreland to the continental hinterland, in a continuous flow of goods without borders. "

This vision of the port is also consented by Notteboom who states in that: "European ports increasingly function not as 
individual entities that manage ships, but rather as supply chains and networks. " [13]

After these various observations, it can be said that the regions have an interest in encouraging maritime trade, and that the ports must be able to meet the requirements of customers in order to be more attractive. The intensity of operations that can be carried out in a port depends on the size of the port and its infrastructure, as some cargoes have specific needs (e.g. frozen products).

\subsection{Containerization}

Containerization is the process of using containers as a means of transferring goods and merchandise. This concept only appeared in the 20th century, but since then it has become an indispensable element in the world of transport. Several elements have contributed to its success, including its multimodal nature, which makes it possible to switch between different modes of transport. This feature, combined with the possibility of geo-localization of cargo, based on computer systems, has quickly seduced exporters and at the same time has contributed to the globalization of trade.

By becoming an international tool, the container was then standardized following agreements between transport companies. Improvements and specifications were then made to make containers more compatible with certain types of cargo. However, the container is not infallible because, although it has many advantages, it has rendered manual controls almost impossible. Therefore, additional efforts have been made to create technical control means. [4]

\subsection{Description and properties of the container}

A container is a rectangular metal box used to store items that are to be transported from one place to another. Due to standardization, the dimensions of containers are regulated by the ISO 668: 1995 standard [2]. The unit of measurement for containers is the 20 -foot equivalent unit (TEU), but there are also containers of 40 feet ( 2 TEU) containers, etc. Generally, there are several container shapes, of which the best known are: standard, high-cube, hard-top, open-top, flatracks, flat, ventilated, insulated and refrigerated, bulk, and tank. [2].

\subsection{Global Impact of the Container}

The most profound impact of the container is on the entire global economy. Worldwide, in the early 2000s, 300 million 20-foot containers were transported by sea each year [4], with more than a quarter of those shipments coming from China. As Slack notes:

"Globalization and containerization have a mutual relationship. There is little doubt that the expansion of global trade and the expansion of global manufacturing systems would have been impossible without the efficiencies and savings that containerization has brought." [14]

Globalization is rightly the subject of many discussions. it has been seen how containers have reduced the number of employees at individual ports. Beyond that, globalization has displaced the employment between cities, regions and countries. It has also reduced costs for consumers and made it possible to deliver a much wider variety of products to many markets. Globalization has affected not only economies, but also the environment, politics and culture. The container, a simple technology that is designed to speed up the loading and unloading of goods, has proven to be an important part of these changes.

\subsection{Different storage strategies}

One of the advantages of using containers is that they can be stacked on top of each other.

However, this advantage has its limits, as it can cause reshuffling, which is mainly done when removing the containers from the bottom of the stacks. Therefore, it is essential for each container terminal to adopt an adequate storage strategy. The different storage methods that exist in the literature can be divided into four categories according to Saanen. [15]

\subsubsection{Segregated and non-segregated}

Segregated storage involves a separation between containers that are exporting (outbound) and those that are importing, while the non-segregated method does not differentiate between container categories. Therefore, containers can be stacked regardless of their destinations. [16]

\subsubsection{Grouping and Dispersion}

With the group storage method, adjacent storage locations are assigned to each set of containers that have the same specifications (e.g., destination, size, contents, refrigeration, empties, etc.). Containers that belong to the same group are assumed to be interchangeable, and therefore, they can be stacked in some way without regard to their departure dates

In contrast to this technique, the dispersed storage method does not attempt to group containers together. They are stored independently of each other. [17]

\subsubsection{Direct storage and indirect storage}

In most port terminals, containers are placed directly in the storage area, where they will remain until their departure.

In contrast, in indirect storage, containers are first placed in a staging area before being transferred to the storage yard. [18]

\subsubsection{Unloading Priority and Load Priority}

Storage methods that priories container unloads seek to maximize the performance of all activities related to storage operations.

In contrast to these methods, those that priorise container loads seek to maximize the performance of retrieval operations [19]

\section{CONTEXTUALISATION OF THE STUDY}

To solve the container storage problem, two cases can be identified: static and dynamic. The main difference between these two cases is the fact that in the static case, all containers are considered to have already arrived at the port before the start of the storage operations; whereas in the dynamic case, Let's consider the containers that will arrive after the start of the storage operations.

\subsection{Classical solving approach}

In this paper, the static case of the container storage problem is treated.

To do so, two types of approaches are adopted: an analytical approach (in which a mathematical model is given and the complexity of the problem is studied) and a numerical approach. 


\subsection{The complexity of the problem}

To study the complexity of the container storage problem, this paper considers the ideal case, in which the storage yard is large enough to allow the shuffle to be prohibited. In addition, it is considered the single-objective version of the problem, in which only the total distance to be traveled between the storage locations and the outlets is minimized.

Initially, in any instance of the container storage problem (CSP), all stacks are initially empty.

\subsection{Case where all stacks are initially empty}

Let's introduce an undirected graph $\mathrm{G}(\mathrm{K} ; \mathrm{T} ; \mathrm{R})=(\mathrm{V} ; \mathrm{E})$, constructed from any instance of the container storage problem, where $\mathrm{K}$ is the set of containers while $\mathrm{T}$ and $\mathrm{R}$ are vectors giving the starting date and size of each container, respectively. The graph $\mathrm{G}(\mathrm{K} ; \mathrm{T} ; \mathrm{R})$ is constructed as follows. A vertex of the graph corresponds to a container. To simplify the notation, the index $\mathrm{k}$ is used to designate both a container and the vertex of the graph that corresponds to it. an edge is between two vertices $\mathrm{k}$ and $\mathrm{k} 0$ if and only if the corresponding containers cannot be stored in the same stack. In other words, if one of the following conditions holds:

_ $\mathrm{k}<\mathrm{k}_{0}$ and $\mathrm{T}_{\mathrm{k}}<\mathrm{T}_{\mathrm{k} 0}$, because in each stack the containers must be stored in the order of their arrival at the port and the descending order of their departure dates,

- $\mathrm{R}_{\mathrm{k}} \neq \mathrm{R}_{\mathrm{k} 0}$, because two containers that have unequal dimensions cannot be stored in the same stack.

The figure is an illustration of a graph constructed from a CSP instance.

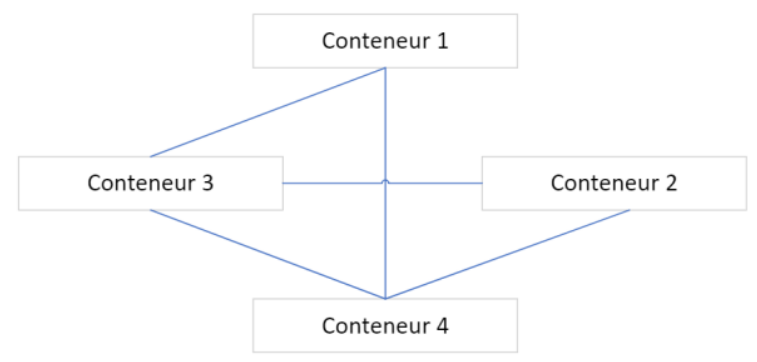

Figure 1: incompatibility chart

This graph is constructed from the following data.

Table 1: dimension and depart date of departure of containers

\begin{tabular}{|c|c|c|}
\cline { 2 - 3 } \multicolumn{1}{c|}{} & Dimension & Date of departure \\
\hline Container 1 & 2 EVP & 12 \\
\hline Container 2 & 2 EVP & 9 \\
\hline Container 3 & 2 EVP & 14 \\
\hline Container 4 & 1 EVP & 19 \\
\hline
\end{tabular}

\subsection{Application and programming on a solver}

\subsubsection{Application to an example of 5 containers}

Let's consider the storage of 5 containers of the same size in 3 stacks that are initially empty. In this example, assume that the containers are equal and that the maximum capacity of a stack is equal to 3 . The departure dates of the containers are given in Table below:

Table 2: date of departure of the 5containers

\begin{tabular}{|c|c|}
\hline Container & Date of departure \\
\hline 1 & 12 \\
2 & 15 \\
3 & 10 \\
4 & 18 \\
5 & 12 \\
\hline
\end{tabular}

The distances used in the example are noted in this table:

Table 3: distances between stacks and exits of containers

\begin{tabular}{|c|c|c|c|c|c|}
\hline $\mathbf{p}$ & $\mathbf{d 1}$ & $\mathbf{d 2}$ & $\mathbf{d 3}$ & $\mathbf{d 4}$ & $\mathbf{d 5}$ \\
\hline $\mathbf{1}$ & 125 & 328 & 225 & 398 & 420 \\
\hline $\mathbf{2}$ & 138 & 411 & 138 & 311 & 433 \\
\hline $\mathbf{3}$ & 126 & 398 & 185 & 352 & 334 \\
\hline
\end{tabular}

The incompatibility graph obtained from the data of the departure date table is shown in this figure.

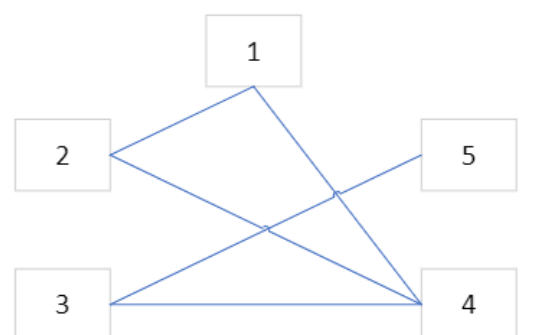

Figure2: incompatibility chart -5 containers

From the graph of the figure and the data of the 1st and 2nd table, following linear program is constructed: 


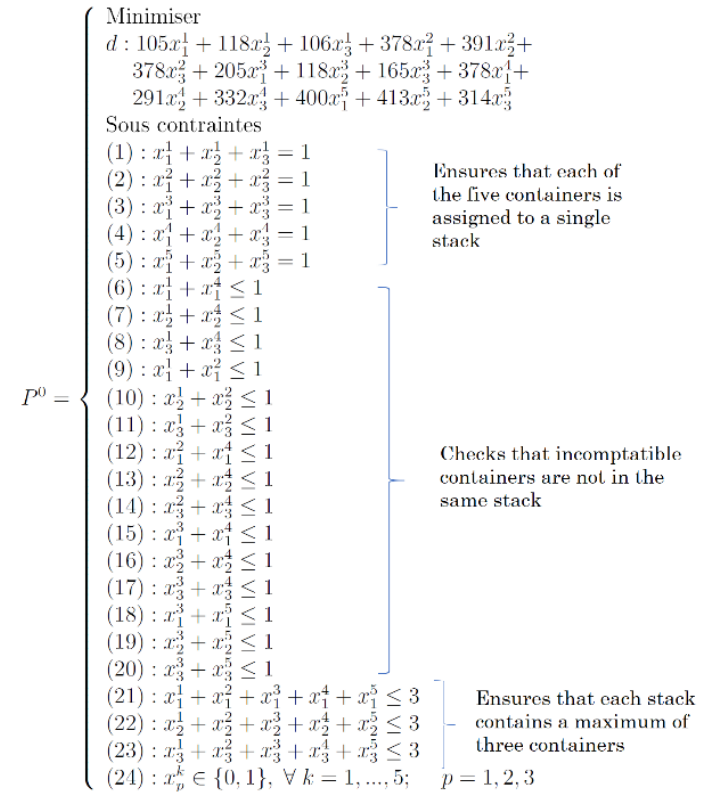

Result of the coding on the solver:

\begin{tabular}{|c|c|}
\hline Solution avec l'obje & \\
\hline Nom & Valeur \\
\hline$\checkmark ?$ Variables de & \\
\hline $10 \times 11$ & 1 \\
\hline $10 \times 12$ & 0 \\
\hline $10 \times 13$ & 0 \\
\hline $10 \times 14$ & 0 \\
\hline 10 $\mathrm{x} 15$ & 0 \\
\hline 10 $x 21$ & 0 \\
\hline $10 \times 22$ & 1 \\
\hline $10 \times 23$ & 1 \\
\hline $10 \times 24$ & 0 \\
\hline $10 \times 25$ & 0 \\
\hline 10 x31 & 0 \\
\hline $10 \times 32$ & 0 \\
\hline $10 \times 33$ & 0 \\
\hline $10 \times 34$ & 1 \\
\hline $10 \times 35$ & 1 \\
\hline
\end{tabular}

This result is valid and satisfies all the constraints of the problem

\subsubsection{Application to an example of 10 containers}

Let's Consider the example of storage of 10 containers of the same size in 3 stacks that are initially empty. In this example, it is assumed that the sizes of containers are equal, and the maximum capacity of a stack is equal to 4 . The departure dates of the containers are mentioned in this table.
Table 4: date of departure of the 10 containers

\begin{tabular}{|c|c|}
\hline Container & Date of departure \\
\hline 1 & 12 \\
2 & 15 \\
3 & 10 \\
4 & 18 \\
5 & 12 \\
6 & 11 \\
7 & 11 \\
8 & 13 \\
9 & 9 \\
10 & 7 \\
\hline
\end{tabular}

The distances used in the example are noted in this table:

Table 5: distances between stacks and exits of containers

\begin{tabular}{|c|c|c|c|c|c|c|c|c|c|c|}
\hline $\mathbf{p}$ & $\mathbf{d 1}$ & $\mathbf{d 2}$ & $\mathbf{d 3}$ & $\mathbf{d 4}$ & $\mathbf{d 5}$ & $\mathbf{d 6}$ & $\mathbf{d 7}$ & $\mathbf{d 8}$ & $\mathbf{d 9}$ & $\mathbf{d 1 0}$ \\
\hline $\mathbf{1}$ & 125 & 328 & 225 & 398 & 420 & 200 & 350 & 520 & 205 & 100 \\
\hline $\mathbf{2}$ & 138 & 411 & 138 & 311 & 433 & 120 & 324 & 118 & 165 & 110 \\
\hline $\mathbf{3}$ & 126 & 398 & 185 & 352 & 334 & 180 & 260 & 400 & 323 & 210 \\
\hline
\end{tabular}

The incompatibility graph obtained from the data of the departure date table is shown in this figure.

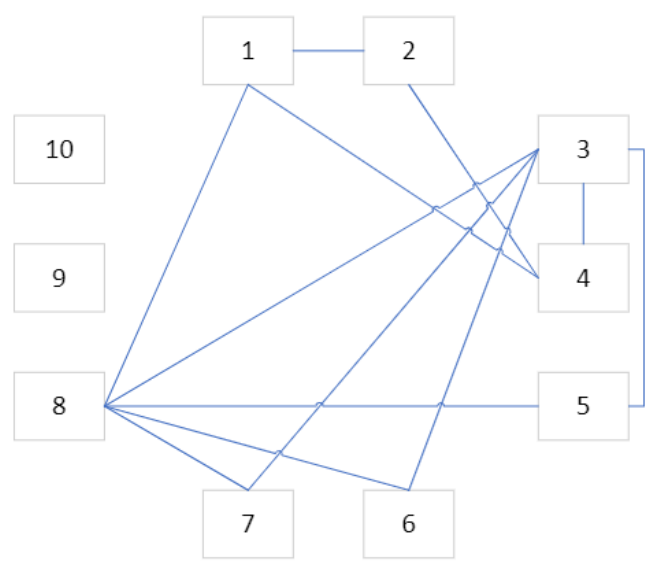

Figure4: incompatibility chart $-\mathbf{1 0}$ containers 
Result of the coding on the solver:

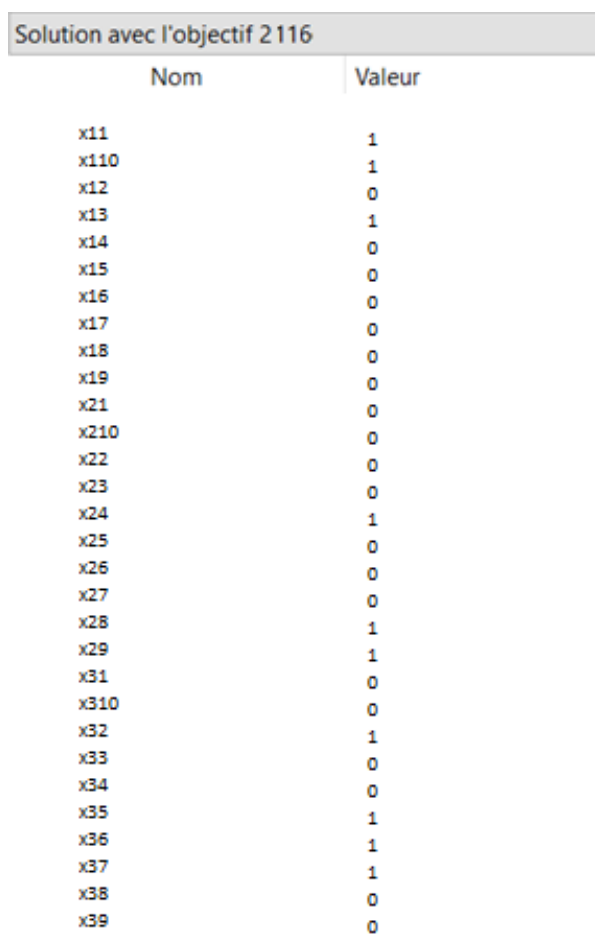

Figure5: Solver results $\mathbf{- 1 0}$ containers

This result is valid and satisfies all the constraints of the problem

\subsubsection{Application to an example of 20 containers}

Let's consider storing 20 containers of the same size in 4 stacks that are initially empty. This example assume that the containers are equal, and that the maximum capacity of a stack is 5 .

The solver does a relaxation of the mathematical problem:

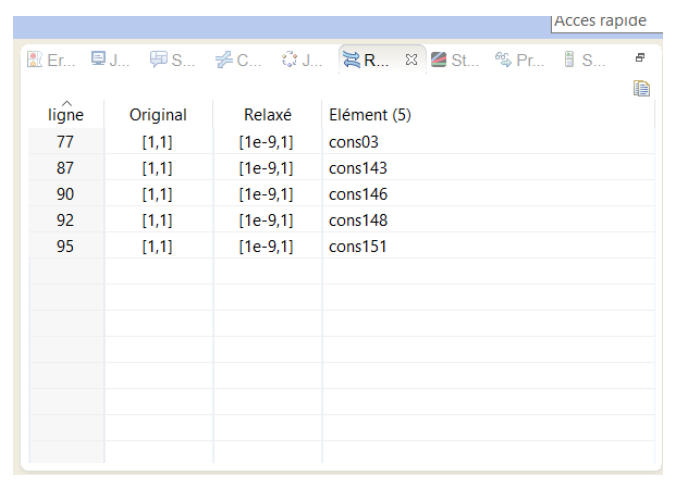

Figure6: problem relaxation $\mathbf{- 2 0}$ containers

by enlarging the complexity of the problem, or enlarging the size of the instance, the solver tries to relax the problem, which may give an invalid solution or one that is not the most optimal or does not satisfy all the constraints.

\section{CONCLUSION}

In this paper, a bibliographical study on the problem of container storage in a port terminal is presented. Different storage strategies are discussed, as well as analytical and numerical solution methods.
The results of the numerical simulations performed with the computer solver, on very small instances, proved the efficiency of the mathematical model. However, since the solver will not be able to solve large instances, and since exact methods are expensive in computation time and computer memory, to circumvent this difficulty and accelerate the resolution of large instances, meta-heuristic algorithms are proposed.

The perspective of this work is to train the model on large instances using metaheuristic algorithms, which will accurately determine the storage location assigned to each container, and which consider incoming containers as well as outgoing or transitioning containers.

\section{REFERENCES}

[1] M. Wang, The rise of container transport in Asia, In : T. W. Lee, Culliane K (eds) World shipping and port development. Palgrave, Basingstoke, pp. 10-35, 2005.

[2] D. Steeken, S. Vob, et R. Stahlbock, Container terminal operation and operations research_a classification and literature review, OR Spectrum, vol. 26, pp. 309-332, 2005.

[3] Hans-Otto Günther et Kap-Haw Kim, Container terminals and terminal operations, OR Spectrum, vol. 28, pp. 437-445, 2006.

[4] M. Levinson, The box : How the shipping container made the world smaller and the world economy bigger, Princeton : Princeton UP, 2006.

[5] F. Broeze, The globalisation of the oceans : Containerisation from the 1950s to the present, St. Johns, NF, Canada : International Maritime Economic History Association, 2002.

[6] H. C. Brookfield, Boxes, ports, and places without ports, In Doyle, B.S. \& Hilling, D. (Eds.), Seaport systems and spatial change, pp. 61-79, Chichester, UK: Wiley, 1984.

[7] B. J. Cudahy, The container revolution : Malcolm McLean's 1956 innovation goes global, TR News 246, pp. 5-9, 2006.

[8] U.S. Army Transportation Museum (n.d.). History \& development of the container. (publication date unknown). Consulté le 29 June 2014 sur http://www.transchool.eustis.army.mil/museum/CONEX. htm

[9] Lloyd's, Containerisation International Yearbook 2012, incl. CD-ROM.

[10] UNCTAD, Review of maritime transport, 2005 : United Nations, 2006.

[11] M. Stopford, Maritime Economics, New York : Routledge, 2009.

[12] P. Hall, R. J. McCalla, C. Comtois, et B. Slack, Integrating seaports and corridors, Farnham, Surrey : Ashgate, 2011.

[13] T. E. Notteboom, Concentration and the formation of multi-port gateway regions in the European container port system: an update, Journal of Transport Geography, vol. 18, pp. 567-583, 2010.

[14] B. Slack, Corporate realignment and the global imperatives of container shipping ,In Pinder, D. \& Slack, B. (Eds.) Shipping and ports in the twenty-_rst century : 
Globalization, technical change and the environment, London : Routledge, pp. 25-39, 2004.

[15] Y. A. Saanen et R. Dekker, Intelligent stacking as way out of congested yards part 1, Port Technol Int, vol. 31, pp. 87-92, 2007.

[16] Y. Ma et K. H. Kim, A comparative Analysis : Various storage rules in container yards and their perfermances, Industrial engineering \& Management systems, vol. 11,pp. 276-287, 2012.
[17] Y. A. Saanen et R. Dekker, Intelligent stacking as way out of congested yards ? part 1, Port Technol Int, vol. 31, pp. 87-92, 2007.

[18] T. Chen, Yard operations in the container terminal-a study in the "unproductive" moves, Marit Policy Manage, vol. 26, pp. 27-38, 1999.

[19] M. B. Duinkerken, J. J. M. Evers, et J. A. Ottjes, A Simulation Model For Integrating Quay Transport And Stacking Policies On Automated Container Terminals, Proceedings of the 15 th European Simulation Multiconference, Prague, 2001. 